\title{
PENERAPAN STRATEGI PQ4R (PREVIEW, QUESTION, READ, REFLECT, RECITE AND REVIEW) TERHADAP HASIL BELAJAR IPA KELAS V SDN MOJOLUHUR KABUPATEN PATI
}

\author{
Heni Meyrawatimayan', M. Yusuf Setia Wardana ${ }^{2}$ Aries Tika Damayani ${ }^{3}$ \\ Surel: Henimeyra15@gmail.com
}

\begin{abstract}
There are 20 students from 27 students whose values are still below the $K K M$ criteria. One alternative strategy that can be applied to improve student learning outcomes to be optimal is to use the PQ4R strategy (Preview, Question, Read, Reflect, Recite and Review). The research that will be conducted by the author is a quantitative study with a preExperimental Design experimental method with the type of One-Group Pretest posttest Design and aims to determine the V-grade science learning outcomes before using the PQ4R strategy (Preview, Question, Read, Reflect, Recite and Review) and after using the PQ4R strategy (Preview, Question, Read, Reflect, Recite and Review.
\end{abstract}

Keywords: Learning Outcomes, PQ4R Strategy

\begin{abstract}
ABSTRAK
Ada 20 siswa dari 27 siswa yang nilainya masih dibawah kriteria KKM.. Salah satu alternative strategi yang dapat diterapkan untuk meningkatkan hasil belajar siswa agar optimal adalah dengan menggunakan strategi $P Q 4 R$ (Preview, Question, Read, Reflect, Recite and Review). Penelitian yang akan dilakukan penulis merupakan penelitian kuantitatif dengan metode ekperimen pre-Experimental Design dengan jenis penelitian One-Group Pretest posttest Design dan bertujuan untuk mengetahui hasil belajar IPA kelas V sebelum menggunakan strategi $P Q 4 R$ (Preview, Question, Read, Reflect, Recite and Review) dan sesudah menggunakan strategi PQ4R (Preview, Question, Read, Reflect, Recite and Review.
\end{abstract}

Kata Kunci: Hasil Belajar, Strategi PQ4R

\section{PENDAHULUAN}

Pendididikan seringkali diartikan dan dimaknai orang secara beragam,bergantung pada sudut pandang masing-masing dan teori yang dipegangnya. Terjadinya perbedaan pemikiran tentang pendidikan dalam konteks akademik merupakan sesuatu yang lumrah, bahkan dapat semakin memperkaya khazanah berfikir manusia dan bermanfaat untuk pengembangan teori itu sendiri. Sedangkan dalam UU no. 20 Tahun 2003 menyatakan bahwa "Pendidikan secara umum adalah usaha sadar dan terencana untuk mewujudkan suasana belajar dan proses pembelajaran untuk peserta didik agar secara aktif mengembangkan potensi dirinya 
untuk memiliki kekuatan spiritual keagamaan, pengendalian diri, kepribadian, kecerdasan, akhlak mulia,serta ketrampilan yang diperlukan dirinya di masyarakat, bangsa dan Negara. Menurut Drijarkara (Suwarno, 2008) inti pendidikan adalah pemanusiaan manusia muda. Pada dasarnya pendidikan adalah pengembangan manusia muda ke taraf insani. Sedangkan Carter V.Good (dalam Suwarno, 2006: 20) pendidikan adalah: pertama, keseluruhan proses dimana sesorang mengembangkan kemampuan, sikap dan bentukbentuk tingkah laku lainnya yang bernilai positif dalam masyarakatditempat dia hidup; kedua, proses social di mana orang dihadapkan pada pengaruh lingkungan yang terpilih dan terkontrol (khusus yang dating dari sekolah), sehingga orang tersebut bisa mendapat atau mengalami perkembangan kemampuan social maupun keampuan individual secara optimal.

Dengan demikian efektivitas pembelajaran yang dilakukan guru sangat berhubungan dengan hasil belajar yang akan dicapai siswa. Sedangkan pembelajaran bisa dikatakan efektif apabila siswa mampu mencerna apapun yang dijelaskan oleh guru serta memberikan pengalaman yang baru bagi siswa itu sendiri serta mengantarkan mereka kepada tujuan yang ingin dicapai. Berdasarkan hasil wawancara dan observasi dengan guru kelas yaitu Pak. Yurike di SDN Mojoluhur menunjukkan fakta dilapangan bahwa peran guru yang hanya sebagai fasilitator belum terlihat malah lebih cenderung terrihat guru menjadi pusat pembelajaran dengan metode yang digunakan adalah metode ceramah.

Menurut penuturan dari Pak. Yurike untuk kegiatan belajar mengajar masih terkendala beberapa hal, yang pertama di $\mathrm{Sd}$ tersebut untuk kelas $\mathrm{V}$ penerapan kurikulum 2013 baru berjalan setahun ini, sedangkan untuk kelas 2 dan 4 sudah terlaksana selama 3 tahun. Kedua, Dari sumber belajar pun belum terpenuhi karena pada kenyataanya guru belum mendapatkan buku guru sebagai pedoman pengajaran, seringkali beliau mencari sumber referensi lain misalnya googling dari internet ataupun mencari buku-buku lain yang berhubungan dengan mata pelajaran. Ketiga, sebagai guru baru tentu beliau belum begitu menguasai pembelajaarn di lapangan, tentu masih merasa kaku atau canggung dalam kegiatan belajar mengajar apalagi salama ini belum ada pelatihan cara mengajar kurikulum K13 untuk guru kelas V, jika adapun hanya formalitas hitam di atas putih saja. Akhirnya hal ini berimbas pada hasil belajar yang diperoleh siswa kelas V khusunya mata pelajaran IPA. Menurut Usman Samatowa (Istanti, 2015) ada 4 alasan penting kenapa IPA harus diajarkan di sekolah dasar. Pertama, bahwa IPA berfaedah bagi suatu bangsa karean 
IPA meruapakan dasar dari teknologi yang menentukan kemajuan pembangunan suatu bangsa. Suatu teknologi tidak akan berkembang pesat tidak didasari pengetahuan dasar yang memadai . sedangkan pengetahuan dasar untuk teknologi adalah IPA. Kedua, bila diajarkan dengan cara yang tepat IPA merupakan suatu mata pelajaran yang membrikan anak berpikir kritis dan objektif. Ketiga, bila diajarkan melalui percobaan-percobaan yang dilakukan sendiri untuk anak pembelajaran IPA tidak hanya hafalan belaka. Keempat, IPA mempunyai nlai-nilai pendidikan yaitu dapat membentuk kepribadian anak secara keseluruhan Dari data yang didapat dari hasil ulangan harian siswa kelas $\mathrm{V}$ menunjukkan bahwa masih banyak sekali siswa yang belum tuntas $\mathrm{kkm}$, dari 27 siswa ada 20 siswa yang nilainya masih di bawah $\mathrm{kkm} /$ belum tuntas

Menurut Hamalik (Wasti, 2013) hasil belajar adalah bila seseorang telah belajar akan terjadi perubahan tingkah laku pada orang tersebut, misalnya dari tidak tahu menjai tahu dan tidak mengerti menjadi mengerti. Adapun Dimyati \& Mudjiono (dalam Parawati, Suryawan, Apsari, 2018: 24) menggaris bawahi bahwa hasil belajar sebagai suatu interaksi antara pembelajar dan tindakan mengajar. Belajar dan hasil belajar tidak mnegnal usia. Henry ford pernah berkata, bukan masalah usia dua puluh atau delapan puluh tahun.
Siapapun yang berhenti belajar adalah orang yang tua, sementara yang terus belajar adalah orang muda. Akhirnya untuk mengatasi masalah ini siswa akan diberikan sebuah treathment atau perlakuan dengan tujuan agar hasil belajar siswa dapat meningkat. Perlakuan tersebut akan dilakukan selama 3 kali pertemuan dengan langkah pertama melakukan kegiatan posttest kepada siswa kemudian diberikan perlakuan dengan penerapan strategi $p q 4 r$ (preview, question, reda, reflect, recite and review), yang kemudian hasilnya akan dilihat pada hasil pretest. Apakah penerapan startegi pq4r (preview, question, reda, reflect, recite and review) berpengaruh terhadap hasil belajar IPA siswa kelas V SDN Mojoluhur?.

$$
\text { Strategi belajar PQ4R }
$$
merupakan bagian dari model-model pembelajaran inovatif berorientasi pada teori kontruktifisme yang digunakan dengan maksud untuk memberikan pengalam belajar yang berbeda dari yang sebelumnya. PQ4R merupakan pengembangan dari strategi PQRST dan startegi SQ3R (Survey, Question, Read, Recite, Review). Pembelajaran PQ4R konstektual merupakan suatu pembelajaran yang memberikan siswa untuk menemukan sendiri konsep pembelajaran melalui kegiatan membaca secara aktif dan sistematis yang dikelola dengan langkah-langkah preview, question, read, reflect, recite dan review dengan menggunakan pendekatan 
kontekstual sebagai landasannya (Kadek Agus Bayu Pramana, 2014).

Muhibbin (Hendi, 2017) berendapat bahwa Strategi pembelajaran PQ4R yang merupakan singkatan dari kata Preview, Question,Read, Reflect, Recite, Review memiliki arti kata "preview" maksudnya membaca selintas dengan cepat, "question" maksudnya menyusun daftar pertanyaan yang relevan dengan teks, "read" maksudnya membaca teks secara aktif untuk mencari jawaban atas pertanyaanpertanyaan yang telah tersusun, "reflect" maksudnya memahami informasi yang dipresentasikan, "recite" maksudnya menghafal atau mengingat kembali setiap jawaban yang telah ditemukan, "review" maksudnya meninjau ulang seluruh jawaban atas pertanyaan yang tersusun pada langkah kedua dan ketiga

Puspitasari (dalam Hendi, 2017: 43-44) mengemukakan bahwa ada beberapa kelemahan dan kenggulan dari strategi PQ4R, berikut penjelasannya: (1) Keunggulan, (a) Sangat tepat digunakan untuk pengajaran pengetahuan yang bersifat deklaratif berupa konsepkonsep, definisi, kaidah-kaidah, dan pengetahuan penerapan dalam kehidupan sehari-hari, (b) Dapat membantu siswa yang daya ingatannya lemah untuk menghapal konsepkonsep pelajaran, (c) Mudah diterapkan pada semua jenjang pendidikan, (d) Mampu membantu siswa dalam meningkatkan keterampilan proses bertanya dan mengomunikasikan pengetahuannya, (e) Dapat menjangkau materi pelajaran dalam cakupan yang luas; (2) Kelemahan, (a) Tidak tepat diterapkan pada pengajaran pengetahuan yang bersifat prosedural seperti pengetahuan keterampilan, (b) Sangat sulit dilaksanakan jika sarana seperti buku siswa (buku paket) tidak tersedia di sekolah (c) Tidak efektif dilaksanakan pada kelas dengan jumlah siswa yang telalu besar karena bimbingan guru tidak maksimal terutama dalam merumuskan pertanyaan.

Penelitian yang akan dilakukan penulis merupakan penelitian kuantitatif dengan metode ekperimen pre-Experimental Design (Non Design) dengan jenis penelitian One-Group Pretest posttest Design. Populasi dalam penelitian ini adalah seluruh siswa SDN Mojoluhur Kecamatan Jaken Kabupaten Pati kelas V yang berjumlah 27 siswa yang terdiri dari 11 siswa perempuan dan 18 siswa laki-laki. Sampel dalam penelitian ini adalah seluruh siswa kelas V SDN Mojoluhur. Dalam penelitian yang akan dilaksanakan nanti peneliti menggunakan teknik sampling non probability sampling yaitu samping jenuh karena jumlah siswa di SDN Mojoluhur hanya 28 siswa. Dalam teknik pengumpulan data menggunakan metode tes dan non tes.

\section{SIMPULAN}


Akhirnya untuk mengatasi masalah hasil belajar tersebut akan diterapkan sebuah strategi untuk memperbaiki kualitas pendidikan. Salah satu alternative strategi pembelajaran yang dapat diterapkan untuk meningkatkan hasil belajar siswa agar optimal adalah dengan menggunakan strategi $P Q 4 R$ (Preview, Question, Read, Reflect, Recite and Review). Dengan menggunakan metode penelitian eksperimen jenis One-Group Pretest posttest Design. Perlakuan akan diberikan selama 3 kali pertemuan dengan menerapkan strategi $P Q 4 R$. penelitian ini bertujuan untuk mengetahui hasil belajar IPA kelas V sebelum menggunakan strategi PQ4R (Preview, Question, Read, Reflect, Recite and Review) dan sesudah menggunakan strategi $P Q 4 R$ (Preview, Question, Read, Reflect, Recite and Review) di SDN Mojoluhur Kecamatan Jaken Kabupaten Pati.

\section{DAFTAR RUJUKAN}

Anam, G. (2015). Penerapan strategi PQ4R (Preview, Question, Read, Reflect, Recite, Review) untuk meningkatkan hasil belajar siswa kelas XI pada sub pokok bahasan sistem peredaran darah di MAN Buntet.

$\begin{array}{cc}\text { Dr. Ni Nyoman } & \text { Parawati, M. I. } \\ \text { (2017). } & \text { Belajar dan }\end{array}$ pembelajaran . Singaraja: Rajawali pers.

Hendi, A. (2017). Pengaruh Strategi Preview, Question, Read, Reflect,Recite, And Review (Pq4r) Untuk Meningkatkan Kemampuan Pemecahan Masalah Matematika Siswa. 42.

Istanti, R. (2015). Pengaruh model Problem Based Learning terhadap motivasi belajar IPA siswa kelas V SDN Gadingan . 2.

Kadek Agus Bayu Pramana, I. W. (2014). Pengaruh penerapan pembelajaran $p q 4 r$ kontekstual terhadap hasil belajar IPS dan sikap peduli lingkungan siswa kelas V SD Gugus 1 Gianyar. 4.

Suwarno, W. (2008). Dasar-dasar ilmu pendidikan. Yogyakarta: Ar-ruzz Media.

Wasti, S. (2013). Hubungan minat belajar dengan hasil belajar mata pelajaran Tata Busana di Madrasah Aliyah Negri 2 Padang. 5. 
ELEMENTARY SCHOOL JOURNAL VOLUME 9, NO. 1, JUNI 2019 